American Journal of Environmental Sciences 6 (2): 130-136, 2010

ISSN 1553-345X

(C) 2010 Science Publications

\title{
Simulation of Vegetative Induced Deformation in an Unsaturated Soil
}

\author{
Nazri Bn Ali and Mu'azu Mohammed Abdullahi \\ Department of Geotechnics and Transportation, Faculty of Civil Engineering, \\ University Technology Malaysia, 81310 UTM Skudai, Johor Bahru, Johor, Malaysia
}

\begin{abstract}
Problem statement: Tree root water-uptake increases soil strength by increasing the soil matric suction due to pore pressure dissipation in a soil mass, inducing increases in vertical total stress or water extraction, the effective stress to which the soil strata is subjected to may also increase. This causes volume change which might be detrimental to geotechnical structures and shallow foundation. Approach: This study proposed a methodology that can be used for the prediction of the root wateruptake and deformation. It was suggested that negative pore-water pressures can be estimated through two-dimensional governing equation for unsaturated soil and was converted to axi-symmetrical form due radially nature of tree roots. Results: The results of the root water-uptake analysis were then used as input for the prediction of ground displacements in a stress-deformation analysis. A volume change was modeled as a result of matric suction change caused by vegetative induced moisture migration. The proposed method was studied and tested against data collected on a case history involving a mature Lime tree on Boulder clay at Stacey Hall, Wolverton, England and mechanical properties of Boulder Clay. The recommended safe planting distance of trees of height, $\mathrm{H}$, from buildings a distance, $\mathrm{L}$, away is in form of $\mathrm{L}: \mathrm{H} \geq 0.5 \mathrm{~m}$ ratio. Conclusion: The predicted results from the two dimensional axi-symmetrical analyses agree well with the measured data in terms of both total vertical displacements and final water contents in the soil. Based on hypothesis, the numerical model developed provides practicing geotechnical engineers an effective tool for designing structures on vadose zones containing vegetation.
\end{abstract}

Key words: Unsaturated soils, metric suction, water-uptake, simulation, deformation

\section{INTRODUCTION}

Trees may tentatively cause moisture loss in the soil within a radial distance approximately equal to the height of the tree. Vegetative induced moisture movement and its subsequent migration to or from atmosphere cause a great deal of soil movement via shrinkage and swelling which causes volume change. This volume change in unsaturated soil can be expressed in terms of deformations or relative movement of the phases of the soils. The water-uptake by vegetation causes changes in matric suction. Matric suction can increase as a result of evaporation and transpiration which results in volume decrease or shrinkage and the opposite process causes results in volume increase or swelling Fredlund and Hung (2001).

Soil settlement occurs whenever there is an increase in effective confining stress, withdrawal of water by plant roots results in change in water pressures and moisture content in the soil. The variation in the moisture content leads to a change in the effective stress that causes a decrease in porosity and void volume which eventually results into volume change in soil. Massive housing estates are founded on unsaturated soil and have to resist deformation associated with external loads and the matric suction changes in the soils, displacements are mostly as a result of changes in matric suction. In prediction of soil movement two fundamental stages are generally involved; an assessment of the changes in moisture conditions and the knowledge of the volumetric strains induced by these change.

The existing models in literature consider a very simplified model for tree root water uptake implemented mainly in the flow equation. Mathur (1999) used Hooke's law to relate vertical effective stress with vertical displacement. Vrugt et al. (2001) developed a three-dimensional root water uptake model based on the one-dimensional model suggested by Raats (1974). The one-dimensional model was extended by incorporating a radial component and a thickness term to the three-dimensional model.

Corresponding Author: Nazri Bn Ali, Department of Geotechnics and Transportation, Faculty of Civil Engineering, University Technology Malaysia, 81310 UTM Skudai, Johor Bahru, Johor, Malaysia 
However, they have not included the mechanical parameters of the soil in their analysis and only water flow has been simulated, without the coupling effect of stress and deformation. Fredlund and Hung (2001), used the two stress state variable approach, conducted a numerical flow and deformation analysis using a onedimensional root water uptake, which changes linearly from maximum value on surface under the tree to zero at depth $\mathrm{z}_{\max }$. A coupled flow and deformation analysis was conducted, which is the first in this area, a doubtful root water uptake and root zone shape was considered, root water-uptake is both space and time dependent. Infect, soil suction is a limiting factor for root water uptake and a horizontal and vertical distribution of roots determines the dispersal of root water uptake, which must be included in the analysis. The assumed root water uptake rate is time independent, which can be argued. Fredlund and Hung (2001) have not validated their model with field measurements, they just reported that the displacement predictions have the same pattern as Bozozuk and Burn (1960) monitoring. A seasonal water variation as a result of root water-uptake was measured by Biddle (1998). This prompted a simulation of seasonal variation of moisture migration to be carried out by Rees and Ali (2006) and explored issues related to the numerical simulation of moisture migration patterns in the unsaturated zone and in the vicinity of established vegetation and which was in good agreement with the measured variation by Biddle (1998).

This study has the following objectives; to employ two-dimensional axi-symmetrical finite element approach to solve the transient partial coupled flow and deformation equations and to simulate the water-uptake and deformation. A simple concept of sink term for uptake was developed by Rees and Ali (2006) and incorporated to two-dimensional governing equation for unsaturated soil and converted to axi-symmetrical form. A two-dimensional axi-symmetrical finite element approach was employed to solve the transient coupled flow and deformation equations. The capillary potential was estimate as a result of the root water-uptake was partial coupled to estimate the deformation as a result of vegetative induced matric suction changes. The model was verified with Fredlund and Hung (2001) with the water-uptake validated with Biddle (1998).

Water-uptake and deformation concepts: According to Fredlund and Hung (2001) stated that the volume change constitutive relations for the unsaturated soils are formulated using the two stress state variables namely; net normal stress and matric suction, thus:

$\sigma^{\prime}=\sigma-u_{\mathrm{a}}-\chi\left(\mathrm{u}_{\mathrm{a}}-\mathrm{u}_{\mathrm{w}}\right)$
Where:

$\chi \quad=$ The effective stress parameter which depends on degree of saturation and it is unity when degree of saturation is $100 \%$ and zero when completely dry

$\left(\mathrm{u}_{\mathrm{a}}-\mathrm{u}_{\mathrm{w}}\right)=$ The matrix suction

$\left(\sigma-u_{\mathrm{a}}\right)=$ The net mean stress

$\sigma \quad=$ The effective stress

$\sigma \quad=$ The total effective stress

$\mathrm{u}_{\mathrm{w}} \quad=$ The effective pore water pressure

$\mathrm{S}_{\mathrm{r}} \quad=$ The degree of saturation as is related to the moisture content in the unsaturated soil and porosity

It is assumed no external load applied, that may cause expulsion of air and consolidation, emphasis is on root water-uptake as it relates effective stress. It is also assumed that the pore-air pressure is the same with atmospheric pressure; this means the distribution of pore-water pressure is equivalent to the metric suction distributions Fredlund and Hung (2001),

$\sigma^{\prime}=\sigma-u_{\mathrm{w}}$

The pore water pressure will be negative quantity in an unsaturated soil and the negative pore water pressure, when expressed in an equivalent head of water is taken to mean the same thing as capillary potential $(\psi)$ :

$\mathrm{u}_{\mathrm{w}}=-\frac{\mathrm{u}_{\mathrm{w}}}{\gamma_{\mathrm{w}}}=-\frac{\gamma_{\mathrm{w}} \mathrm{h}}{\gamma_{\mathrm{w}}}=\psi=-\mathrm{h}$

Therefore Eq. 2 becomes:

$\sigma^{\prime}=\sigma-\psi$

In groundwater field, the soil deformation is studied as due to extraction of groundwater. The continuity principal applied to the flow in two directions in a referential element yields the twodimensional axi-symmetric domain:

$\left(\frac{\mathrm{V}_{\mathrm{r}}}{\mathrm{r}}+\frac{\partial \mathrm{V}_{\mathrm{r}}}{\partial \mathrm{r}}+\frac{\partial \mathrm{V}_{\mathrm{z}}}{\partial \mathrm{z}}\right) \mathrm{V}_{\mathrm{T}}=\frac{\partial \mathrm{V}_{\mathrm{w}}}{\partial \mathrm{t}}$

Where:

$\mathrm{V}_{\mathrm{T}}=$ Total volume of soil

$\mathrm{V}_{\mathrm{w}}=$ The volume of water in the soil pores

For a constant volume $\mathrm{V}_{\mathrm{T}}$ and expressing Eq. 5 employing Darcy's Law expressed for flow in an 
unsaturated soils. The total potential for the moisture flow taken as the sum of the pressure or capillary potential and the gravitational potential, follows:

$$
\begin{aligned}
\frac{\partial \theta}{\partial \psi} \cdot \frac{\partial \psi}{\partial \mathrm{t}}= & \frac{\partial}{\partial \mathrm{z}}\left[\mathrm{K}(\psi) \frac{\partial \psi}{\partial \mathrm{z}}\right]+\frac{1}{\mathrm{r}} \mathrm{K} \frac{\partial \psi}{\partial \mathrm{r}}+ \\
& \frac{\partial}{\partial \mathrm{r}}\left[\mathrm{K}(\psi) \frac{\partial \psi}{\partial \mathrm{r}}\right]+\frac{\partial \mathrm{K}(\psi)}{\partial \mathrm{z}}-\mathrm{S}(\psi, \mathrm{r}, \mathrm{z})
\end{aligned}
$$

Where:

$\mathrm{K}=$ The unsaturated hydraulic conductivity

$\mathrm{t}=$ The time

$\mathrm{x}, \mathrm{z}=$ The Cartesian coordinate

$\theta=$ The volumetric moisture content

$\psi=$ The capillary potential, S(r, z) is the root water extraction function

$\mathrm{r} \quad=$ The radial coordinate

The root water-uptake extraction function is the sink term $S(\psi, z, r)$ in the Eq. 6 , is given by the equation for water-uptake for two-dimensional axi-symmetric is Rees and Ali (2006):

$\mathrm{S}(\psi, \mathrm{z}, \mathrm{r})=\frac{4 \mathrm{~T}}{\mathrm{z}_{\mathrm{r}} \mathrm{r}_{\mathrm{r}}} \alpha(\psi)\left[1-\frac{\mathrm{z}}{\mathrm{z}_{\mathrm{r}}}\right]\left[1-\frac{\mathrm{r}}{\mathrm{r}_{\mathrm{r}}}\right]$

Where:

$r_{r}=$ The maximum rooting depth in the radial direction $\mathrm{z}_{\mathrm{r}}=$ Maximum rooting depth

$r=$ The radial distance from the origin of the plant trunk $\mathrm{z}=$ Depth in the soil profile

The numerical solution of Eq. 6 via the finite element spatial discretization procedure and a finitedifference time-stepping scheme particular adopting a Galerkin weighted residual approach which will yield the disctretized matrix form with added deformation component for full detail see Rees and Ali (2006):

$\mathrm{K} \underline{\psi}+\mathrm{C} \underline{\dot{\psi}}+\underline{\mathrm{J}}+\underline{\mathrm{S}}=0$

The parabolic shape functions and eight-node isoperimetric elements are employed Zienkiewicz and Taylor (1989). The time-dependent nature of Eq. 8 is dealt with via a mid-interval backward difference technique, yielding;

$$
\underline{\mathrm{K}}^{\mathrm{n}+1 / 2} \underline{\Psi}^{\mathrm{n}+1}+\underline{\mathrm{C}}^{\mathrm{n}+1 / 2}\left[\frac{\underline{\Psi}^{\mathrm{n}+1}-\underline{\Psi}^{\mathrm{n}}}{\Delta \mathrm{t}}\right]+\underline{\mathrm{J}}^{\mathrm{n}+1 / 2}+\underline{\mathrm{S}}^{\mathrm{n}+1 / 2}=0
$$

The capillary potential $(\psi)$ was estimated from Eq. 6 which was used as an input for the stress- deformation analysis. This relationship was established to perform the necessary deformation estimation:

$$
\frac{\partial \varepsilon}{\partial \psi}=\frac{1}{\mathrm{~V}_{\mathrm{T}}} \frac{\partial \mathrm{V}_{\mathrm{v}}}{\partial \mathrm{t}}=\frac{1}{\mathrm{H}_{\mathrm{T}}} \frac{\partial \mathrm{V}_{\mathrm{v}}}{\partial \psi}
$$

For a laterally confined soil, the change in volume is proportional to the change in soil matrix thickness and the initial volume is proportional to the initial thickness.

The elasticity parameters are functions of the stress state of the soil, net normal stress and the metric suction. The elasticity parameters could be estimated using equation from Fredlund and Hung (2001), they were coded into FORTRAN code.

While the soil is normally consolidated clay with a consolidation behavior that can be described by:

$$
\mathrm{de}=\mathrm{C}_{\mathrm{c}} \ln \left(\frac{\sigma_{\mathrm{v}}+\Delta \sigma_{\mathrm{v}}-\mathrm{u}_{\mathrm{wf}}}{\left(\sigma_{\mathrm{v}}-\mathrm{u}_{\mathrm{a}}\right)+\left(\mathrm{u}_{\mathrm{a}}-\mathrm{u}_{\mathrm{w}}\right)_{\mathrm{e}}}\right)
$$

Where:

de $=$ The change of void ratio in the element

$\mathrm{C}_{\mathrm{c}}=$ The compression index, is the swelling/shrinkage deformation,

Cs $\quad=$ The swelling index

$\sigma_{\mathrm{v}} \quad=$ The vertical total stress

$\Delta \sigma_{\mathrm{v}} \quad=$ The change in the total vertical stresses

$\mathrm{u}_{\mathrm{wf}} \quad=$ The final pore water pressure

$\left(\mathrm{u}_{\mathrm{a}}-\mathrm{u}_{\mathrm{w}}\right)_{\mathrm{e}}=$ The metric suction equivalent Fredlund and Rahardjo (1993)

The boundary condition for the stress-deformation analysis involved having the soil free to move in the vertical direction and fixed in horizontal direction at the left and right sides of the domain and the lower boundary would be fixed in both directions.

\section{MATERIALS AND METHODS}

The mesh consists of 8-noded isoperimetric linear strain quadrilateral elements with 8-displacement and 8pore pressure nodes placed at the corners of each element. The entire finite element mesh consists of 1281 nodes and 400 elements; the axi-symmetric domain is shown in Fig. 1. The mesh was configured to offer some refinement within the root zone area since this is the region where the most significant moisture content variations were expected to occur. The boundary condition for the stress-deformation analysis in involved having the soil free to move in the vertical direction and fixed in horizontal direction at the left and 
right sides of the domain and the lower boundary would be fixed in both directions. The simulation employs a time-step size of $21600 \mathrm{sec}$, which was held constant for the entire period considered. A mature Lime tree of $15 \mathrm{~m}$ height on boulder clay was considered for this analysis. The soil parameters are shown in Table 1 which is typical values for Boulder clay.

The required soil moisture retention characteristics and unsaturated hydraulic conductivity would be simulated from the closed form equation developed by Van Genuchten, (1980), thus:

$\theta(\psi)=\theta_{\mathrm{r}}+\frac{\left(\theta_{\mathrm{s}}-\theta_{\mathrm{r}}\right)}{\left[1+|\alpha \psi|^{\mathrm{n}}\right]^{\mathrm{m}}} \quad \begin{aligned} & \psi \geq 0 \\ & {\left[\begin{array}{l}{[1+0}\end{array}\right.}\end{aligned}$

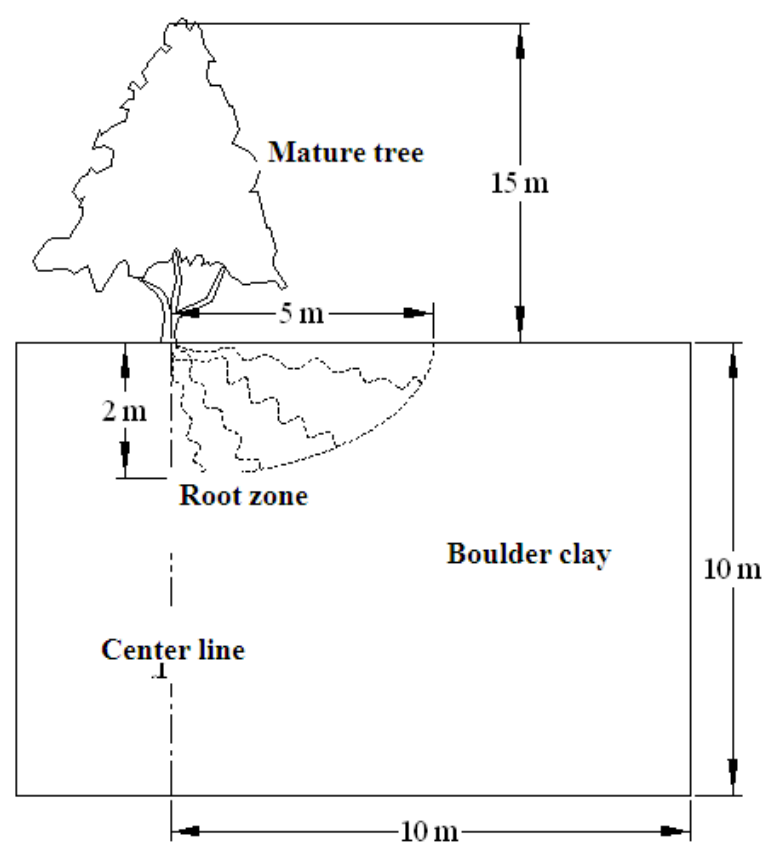

Fig. 1: Axi-symmetric domain

Table 1: Parameters used in the analysis

\begin{tabular}{lll}
\hline Parameters & Values & Reference \\
\hline $\mathrm{k}_{\mathrm{s}}$ & $10^{-6} \mathrm{~m} \mathrm{sec}^{-1}$ & Biddle (1998) \\
$\mathrm{T}_{\mathrm{p}}$ & $5 \mathrm{~mm} \mathrm{day}^{-1}$ & Biddle $(1998)$ \\
$\Psi_{\mathrm{d}}$ & $1500 \mathrm{kPa}^{-3}$ & Fatahi et al. $(2009)$ \\
$\gamma$ & $21 \mathrm{kN} \mathrm{m}^{-3}$ & Indraratna et al. $(2006)$ \\
$\mathrm{e}_{0}$ & 0.60 & Powrie et al. $(1992)$ \\
$\mathrm{C}_{\mathrm{c}}$ & 0.13 & Indraratna et al. $(2006)$ \\
$\mu$ & 0.30 & Indraratna et al. $(2006)$ \\
$\theta_{\mathrm{r}}$ & 0.1 & Rees and Ali $(2006)$ \\
$\theta_{\mathrm{s}}$ & 0.4 & Rees and Ali (2006) \\
$\alpha$ & 0.00280 & Rees and Ali (2006) \\
$\mathrm{m}$ & 0.29 & Rees and Ali (2006) \\
$\mathrm{n}$ & 1.4 & Rees and Ali (2006) \\
1 & 0.5 & Rees and Ali (2006) \\
\hline
\end{tabular}

$$
\mathrm{K}=\mathrm{Ks} \frac{\left[\left(1+|\alpha \psi|^{\mathrm{n}}\right)^{\mathrm{m}}-|\alpha \psi|^{\mathrm{n}-1}\right]^{2}}{\left(1+|\alpha \psi|^{\mathrm{n}}\right)^{\mathrm{m}(1+2)}}
$$

Where:

$\theta_{\mathrm{s}} \quad=$ Saturated water content

$\theta_{\mathrm{r}} \quad=$ Residual water content

$\Psi=$ Suction head $(\mathrm{cm})$

$\mathrm{n}, \mathrm{m}, \alpha=$ Empirical shape fitting parameters estimated by fitting Eq. 12 and 13 to the experimental data

$\mathrm{K}$ and $\mathrm{K}_{\mathrm{s}}=$ Unsaturated hydraulic conductivity and saturated hydraulic conductivity respectively while 1 is a soil specific parameter generally assumed to be 0.5

Model verification: The numerical results seem to agree with Fredlund and Hung (2001) analysis, the difference is about 5\%. The slight disparity between the two results is as result of the fact that, two entirely different unsaturated soil models are used in this study and the two different theories influence the volume of change of an unsaturated soil differently.

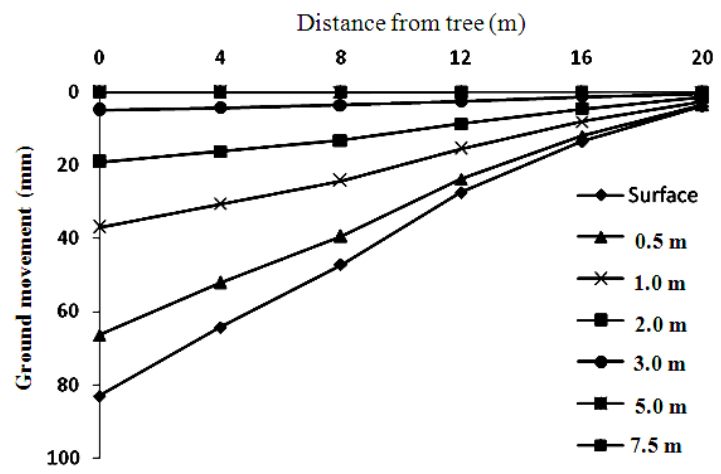

Fig. 2: Variation of ground movement with depth near a tree for the current research

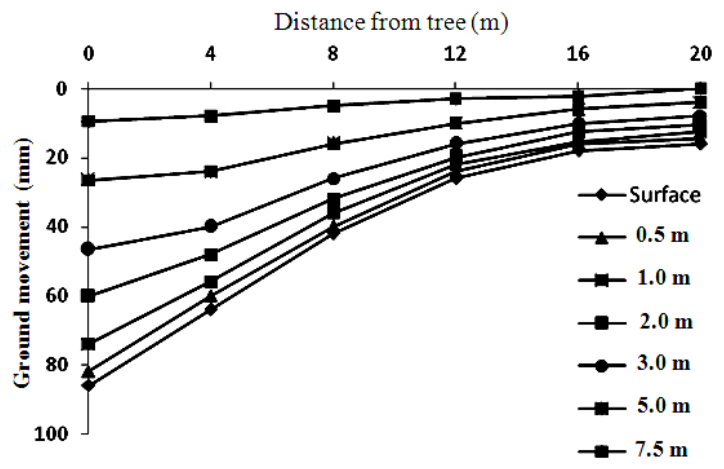

Fig. 3: Variation with depth of ground movements near a tree Modified after Fredlund and Hung (2001) 
Another likely factor is that the former considered that the water uptake is only time dependent while the former considered both time and space dependency as well axi-symmetric domain are used. The water uptakes was validated with Biddle (1998) and see Rees and Ali (2006). The results were shown in Fig. 2 and 3 for comparison between the current work and that Fredlund and Hung (2001) for ground movement respectively.

\section{RESULTS}

The results are shown in Fig. 4, 6 and 8 for the final matric suction for 30, 190 and 360days respectively while Fig. 5, 7 and 9 shows ground settlement for 30, 190 and 360 days respectively. Contour profiles for 190 and 360 days are shown in Fig. 10 and 11 respectively.

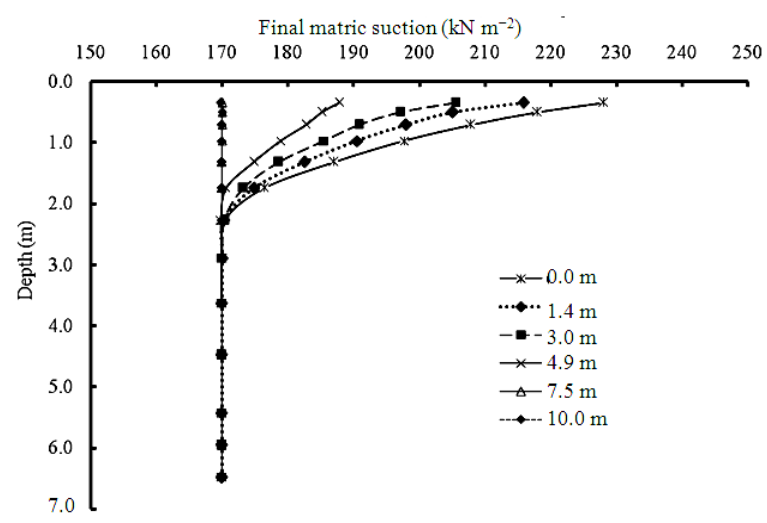

Fig. 4: Variations of final matric suction with depth at various lateral distance from Lime Tree after 30 days

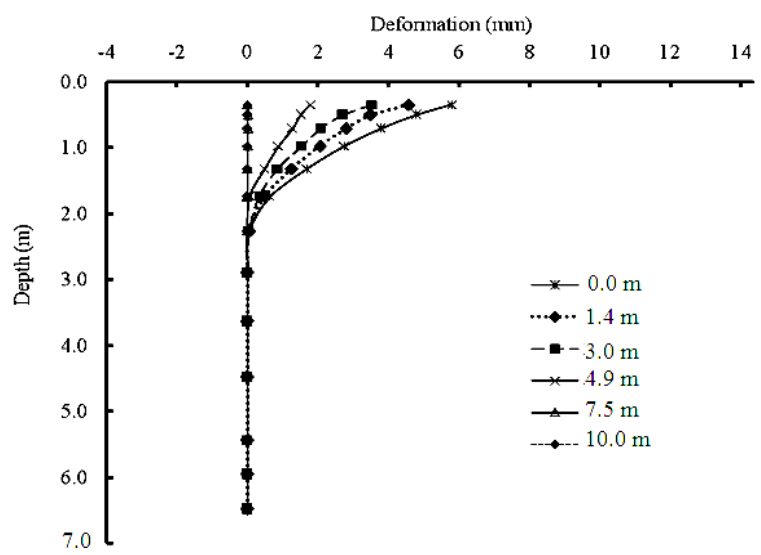

Fig. 5: Variations of ground settlement with depth at various lateral distance from Lime Tree after 30 days
Final Matric Suction $\left(\mathrm{kN} / \mathrm{m}^{2}\right)$

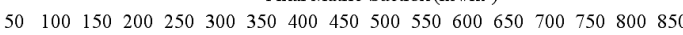

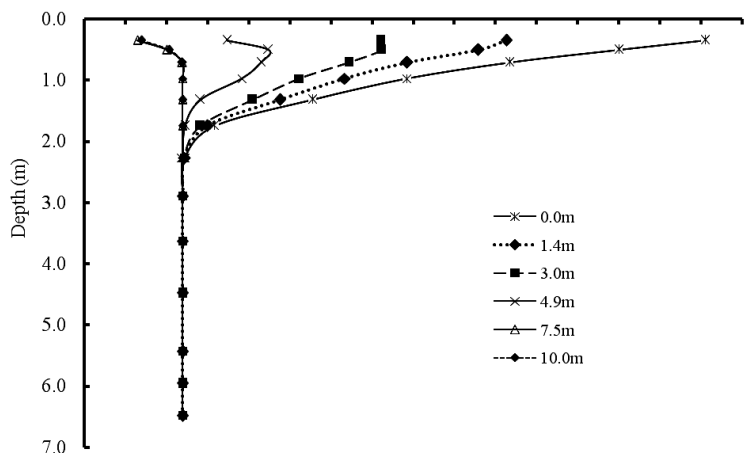

Fig. 6: Variations of final matric suction with depth at various lateral distance from Lime Tree after 190 days

Deformation (mm)

$\begin{array}{lllllllllllllllll}-10 & -5 & 0 & 5 & 10 & 15 & 20 & 25 & 30 & 35 & 40 & 45 & 50 & 55 & 60 & 65 & 70\end{array}$

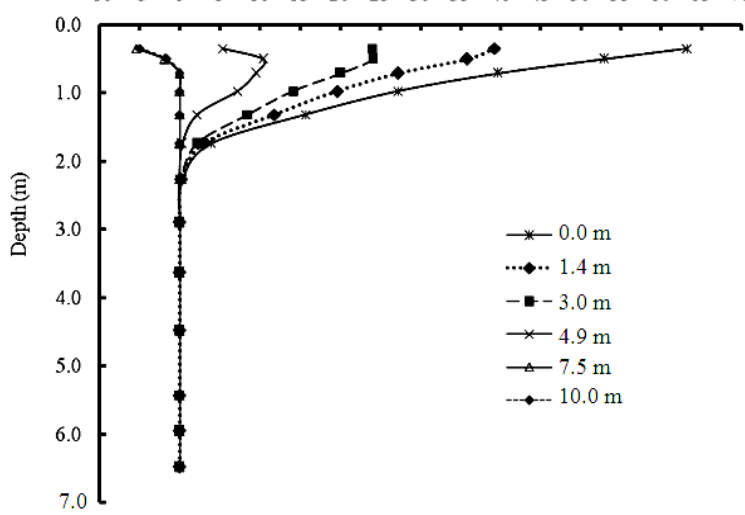

Fig. 7: Variations of ground settlement with depth at various lateral distance from Lime Tree after 190 days

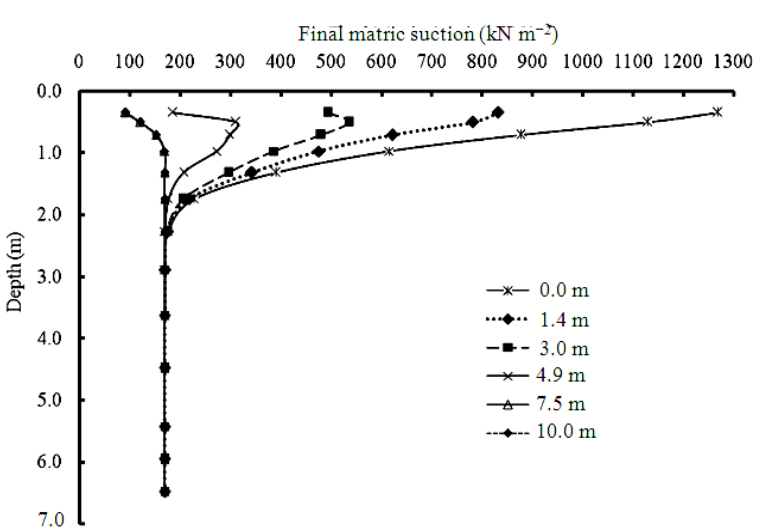

Fig. 8: Variations of final matric suction with depth at various lateral distance from Lime Tree after 360 days 
Am. J. Environ. Sci., 6 (2): 130-136, 2010

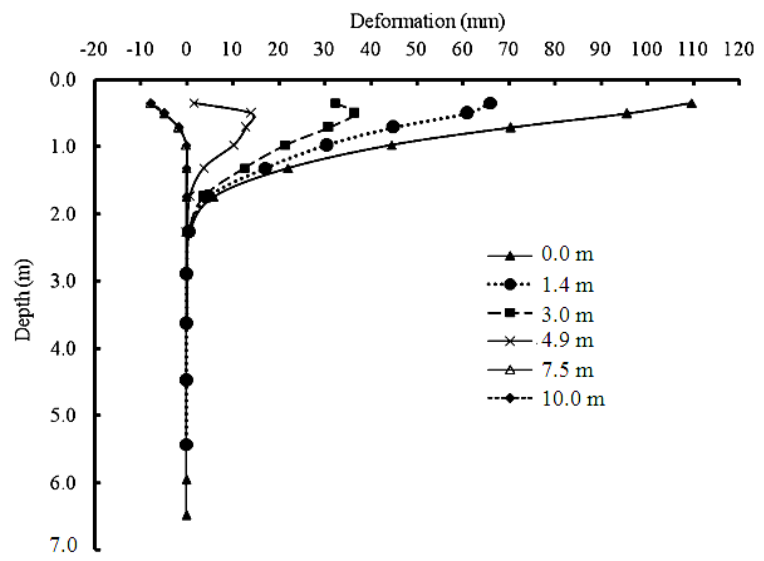

Fig. 9: Variations of ground settlement with depth at various lateral distance from Lime Tree after 360 days

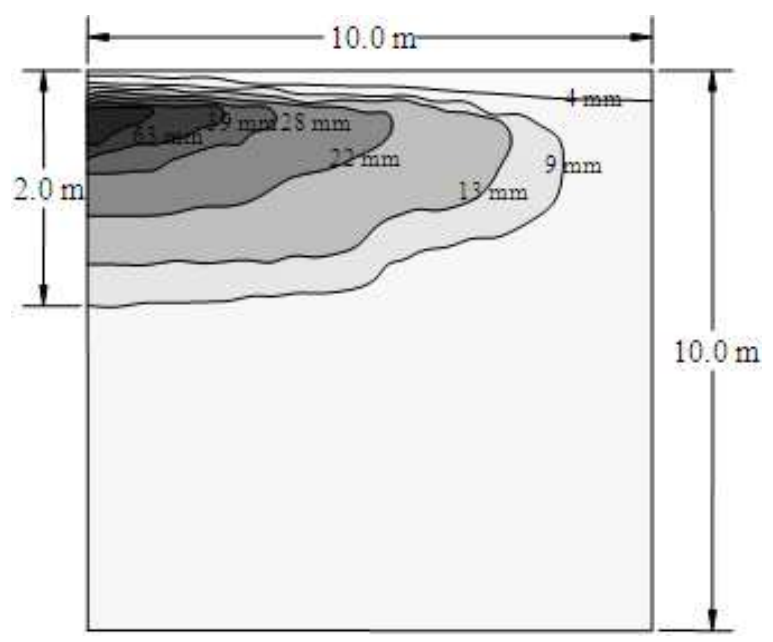

Fig. 10: Deformation contour at 190 days

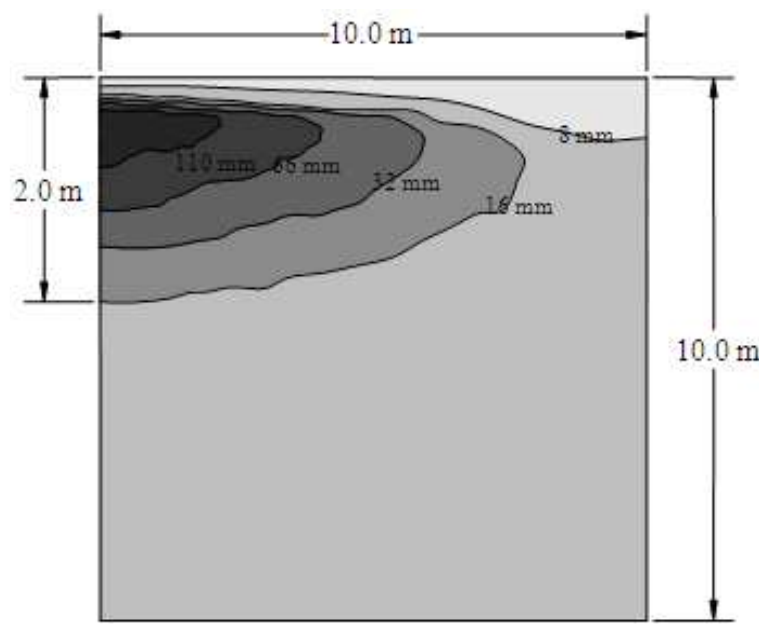

Fig. 11: Deformation contour at 360 days

\section{DISCUSSION}

The magnitude of volume change as a result of vegetative moisture uptake depends much on, not only on the rate of transpiration but also to a greater extends on the soil types and its properties such as degree of compressibility, shrinkage and swelling indices. The vegetative induced ground movement might be as a result of vegetative moisture induced migration which causes change in strain resulting from an increased in matric suction. This partly attributed to root water-uptake which causes changes in volume of void and porosity. The assemblage of soil particles and voids is commonly referred to as the soil matrix or the soil skeleton. The voids may be either filled with water or air or with both. There is a phase relationship between the voids, soil grains and the total volume of matrix itself.

The results shows general decrease in ground movement as the radial distance increase further away from the tree trunk as can be seen in Fig. 5, 7 and 9 for one month, six months and one year respectively. Meanwhile the magnitude of ground movement increase with time. The effect of rainfall was included; rainfall data provided by the Bureau of Meteorology (2006) has been acquired for the nearest weather station to the Wolverton Hampshire site. Figure 7 and 8 shows the simulated period that covers a spring/summer soildrying phase of 6 months followed by an autumn/winter 6 month recharge phase. The sink term was activated, to represent water uptake by transpiration, during spring/summer soil-drying phase and deactivated during the autumn/winter recharge phase. Therefore, the deformation simulation also followed that pattern.

The matric suction decrease as the distance from the trunk mature Lime tree increases as shown in Fig. 4, 6 and 8 for one month, six months and one year respectively. From the data gathered for far the likely safe recommended planting distance from a geotechnical structure taking into consideration the mature Lime Tree of $15 \mathrm{~m}$ height on Boulder Clay at Stacey Hall Wolverton, England and mechanical properties of Boulder Clay, the recommended safe planting distance of trees of height, $\mathrm{H}$, from buildings a distance, $\mathrm{R}$, away is from $\mathrm{L}: \mathrm{H} \geq 0.5 \mathrm{~m}$ ratio.

As expected, the ground settlement that is induced by the soil consolidation, decreased with depth. The ground settlement is caused by both the root water uptake and the evaporation from the soil surface. The rest of the settlement is assumed to be induced by transpiration from the tree leaves. Soil matric suction induced by tree root water uptake propagates radially.

Figure 10 and 11 presents the simulated contours of deformation (in $\mathrm{mm}$ ) generated by the simulation at 
6 and 12 months respectively. Figure 10 and 11 provide further illustration of an overall deformation pattern.

\section{CONCLUSION}

This particular approach together with other factors could be utilized to specify the safe optimal distance between a tree and shallow foundation/building. The concluded study has successfully verified the developed numerical model using the existing literature. The model is capable of predicting soil moisture content and metric suction distributions in the vicinity of vegetation considering various atmospheric condition, plant specifications and ground conditions, as elaborated previously. The likely safe recommended planting distance from a shallow building foundation can estimated taking into consideration the Lime Tree of $15 \mathrm{~m}$ height on Boulder Clay at Stacey Hall Wolverton, England and mechanical properties of Boulder Clay. The recommended safe planting distance of trees of height, $\mathrm{H}$, from shallow foundation buildings a distance, $\mathrm{L}$, away is from $\mathrm{L}: \mathrm{H} \geq 0.5 \mathrm{~m}$ ratio. The results of this study provide a valuable and a relatively accurate means to estimate the influences of vegetation on ground. The numerical model developed provides practicing geotechnical engineers an effective tool for designing structures on vadose zones containing vegetation. The verification exercise confirms that if the relevant parameters are known, then the current finite element model can predict the matric suction generated and the ground deformation caused by vegetative induced moisture movement.

\section{REFERENCES}

Biddle, P.G., 1998. Tree Root Damage to Buildings, Pattern of soil Drying in Proxinity to Trees on Clay Soils. 1st Edn., Vol. 2, Willow mead Publishing Ltd, Wantage, ISBN: 0-9533086-0-X, pp: 88-93.

Bozozuk, M. and K.N. Burn, 1960. Vertical ground movement near Elm trees. Geotechnique, 10: 19-32. http://nparc.cisti-icist.nrc-

cnrc.gc.ca/npsi/ctrl?action=rtdoc $\& a n=5329520 \&$ arti cle $=2 \&$ lang $=$ en

Fatahi, B., H. Khabbaz and B. Indraratna, 2009. Parametric studies on bioengineering effects of tree root-based suction on ground behavior. Ecolog. Eng. 35: 1415-1426. DOI: 10.1016/J.ecoleng.2009.05.014
Fredlund, D.G. and H. Rihardjo, 1993. Soil Mechanics for Unsaturated Soil. 1st Edn., John Wiley and Sons Inc., New York, ISBN: 0-471-85008-X, pp: 346-373.

Fredlund, D.G. and V.Q. Hung, 2001. Predictive of volume change in an expensive soil as a result of vegetation and environmental changes. Proceeding of ASCE Conference on Expansive Clay Soils and Vegetative Influence on Shallow Foundations, Oct. 10-13, Geotechnical Special Publication, Houston, Texas, Reston, pp: 24-43.

Indraratna, B., B. Fatahi and H. Khabbaz, 2006. Numerical analysis of matric suction effects of the roots. Geotech. Eng. 159: 77-90.

Mathur, S., 1999. Settlement of soil due to water uptake by plant roots. Int. J. Numer. Anal. Methods Geomech., 23: 1349-1357.

Bureau of Meteorology, 2006. Meteorological Rainfall Data (1979-1980). United Kingdom Bureau of Meteorology, Meteorological Office, Exeter, United Kingdom.

Powrie, W., J.N. Davies and A.M. Britto, 1992. A cantiliver retaining wall supported by a berm during the temporary work activities. Proceeding of the ICE Conference on Retaining Structures, (RS'92), ICE, Robinson College, Cambridge, pp: 418-428.

Raats, P.A.C., 1974. Steady flows of water and salt in uniform soil profiles with plant roots. Soil Sci. Am. Proc., 38: 717-722. PMID: 17740016.

Rees, S.W. and N. Ali, 2006. Seasonal water uptake near trees: A numerical and experimental study. Geomech. Geo-Eng., 1: 129-138. DOI: $10.1080 / 17486020600823855$

Van Genuchten, M.T., 1980. A closed-form equation for predicting the hydraulic conductivity of unsaturated soils. Soil Sci. Soc. Am. J., 44: 892-898. http://www.ars.usda.gov/SP2UserFiles/Place/53102 000/pdf_pubs/P0682.pdf

Vrugt, J.A., J.W. Hopmans and J. Simunek, 2001. One, two and three-dimensional root water-uptake function for transient modeling. Water Resour. Res., 37: 2457-2470.

Zienkiewicz, O.C. and R.L. Taylor, 1989. The Finite Element Method. 4th Edn., Vol. 1, McGraw-Hill, USA., pp: 648. 